

\title{
Diagnóstico da relação entre a comunidade e o Geopark Araripe: geossítios colina do Horto e Pontal da Santa Cruz, Região Metropolitana do Cariri (RMC), Ceará
}

\author{
Diagnosis of the relationship between the community and the \\ Araripe Geopark: Geosites Colina of Horto and Pontal of Santa \\ Cruz, Metropolitan Region of Cariri, Ceará
}

\begin{abstract}
Marcelo Martins de Moura-Fé
Universidade Regional do Cariri (URCA). Geógrafo. Professor Doutor do Departamento de Geociências da Universidade Regional do Cariri (DEGEO/URCA). Coordenador e pesquisador do Núcleo de Estudos Integrados em Geomorfologia, Geodiversidade e Patrimônio (NIGEP). Bolsista Produtividade em Pesquisa (BPI-Funcap). Docente do Programa de Pós-Graduação em Desenvolvimento Regional Sustentável da Universidade Federal do Cariri (PRODER/UFCA). E-mail: marcelo.mourafe@urca.br
\end{abstract}

\section{Raquel Landim Nascimento} Universidade Regional do Cariri (URCA). Graduanda em Geografia (DEGEO/URCA). Bolsista de Iniciação Científica (PIBIC/URCA) e membra do NIGEP. E-mail: raquellandimnasc123@gmail.com

\section{Maria Andressa Alencar Cardoso Universidade Regional do Cariri (URCA). Graduanda em Geografia (DEGEO/URCA). Bolsista de Extensão (Proex/URCA) e membra do NIGEP. \\ E-mail: andressaalencar528@gmail.com}

RESUMO

O território do GeoPark Araripe apresenta uma notável geodiversidade, originada por uma história geológicageomorfológica antiga e significativa, a qual coaduna com eventos importantes da história natural da Terra. Além de promover a conservação desse patrimônio natural, o GeoPark Araripe tem como objetivo básico fomentar a utilização conservacionista dos seus geossítios em consonância com o desenvolvimento socioeconômico sustentável das comunidades locais, através de projetos de educação (geoeducação) e turismo sustentável (geoturismo). Nesse contexto o objetivo deste trabalho é realizar um diagnóstico da relação entre as comunidades do Horto e do Pontal de Santa Cruz e os geossítios do GeoPark Araripe situados no seu entorno: geossítio Colina do Horto, em Juazeiro do Norte, e geossítio Pontal de Santa Cruz, em Santana do Cariri. Metodologicamente, o embasamento teórico-conceitual tratou do estudo, análise e abordagem do conceito de geodiversidade e suas temáticas relacionadas; associado a um contingente técnico-científico, subdividido em etapas de gabinete, campo e laboratório. Como principais resultados verificou-se nas comunidades que a população necessita de maiores informações sobre o que é o GeoPark Araripe, o que são os geossítios e a respeito dos motivos que levaram a área onde residem, se tornar parte do território de um geoparque. Projetos de educação ambiental, patrimonial mais regulares, bem como, iniciativas de atividades socioeconômicas 
Diagnóstico da relação entre a comunidade e o

Geopark Araripe: geossítios colina do Horto e Pontal da

Santa Cruz, Região Metropolitana do Cariri (RMC),

\section{Júlia Leopoldino Silva}

Universidade Regional do Cariri (URCA). Graduanda em Geografia (DEGEO/URCA). Bolsista de Iniciação Científica

(PIBIC/URCA) e membra do NIGEP. E-mail: julialeopoldino20@hotmail.com

\section{Mônica Virna de Aguiar Pinheiro}

Universidade Regional do Cariri (URCA). Geógrafa. Doutora em Ciências Marinhas Tropicais (Labomar/UFC). Professora do DEGEO/URCA. Vice-coordenadora e pesquisadora do NIGEP.

E-mail:monivirna@yahoo.com.br

Recebido em: 02/1/2018 I Aceito em: $12 / 02 / 2019$ ligadas ao turismo sustentável e o geoturismo poderão dirimir esse quadro e levar, efetivamente, o GeoPark Araripe para o cotidiano das pessoas, aproximando-o de um dos seus objetivos básicos, o desenvolvimento sustentável das comunidades locais no seu território.

Palavras-chave: Geodiversidade. Geoconservação. Geoturismo. Geoeducação. Geocultura.

\section{ABSTRACT}

The territory of the Araripe GeoPark presents a remarkable geodiversity, originated by an ancient and significant geological-geomorphological history, which fits in with important events in the Earth's natural history. In addition to promoting the conservation of this natural heritage, Araripe GeoPark has as its basic objective to promote the conservationist use of its geosites in harmony with the sustainable socioeconomic development of local communities through geoeducation and sustainable tourism (geotourism) projects. In this context, the objective of this work is to diagnose the relationship between the communities of Horto and Pontal of Santa Cruz and the geosites of Araripe GeoPark located in its surroundings: geosite Colina do Horto, in Juazeiro do Norte, and geosite Pontal de Santa Cruz in Santana do Cariri. Methodologically, the theoretical-conceptual foundation dealt with the study, analysis and approach of the concept of geodiversity and its related themes; associated with a technical-scientific contingent, subdivided into office, field and laboratory stages. As the main results, it has been verified in the communities that the population needs more information about what is the Araripe GeoPark, what are the geosites and with respect to the reasons that led the area where they reside, to become part of the territory of a geopark. More regular environmental and patrimonial educational projects, as well as socioeconomic initiatives related to sustainable tourism and geotourism, can resolve this situation and effectively bring the Araripe GeoPark into everyday life of people, bringing it closer to one of its basic objectives, the sustainable development of local communities in their territory.

Keywords: Geodiversity. Geoconservation. Geotourism. Geoeducation. Geoculture. 


\section{INTRODUÇÃO}

Geoparques, geograficamente, são territórios com limites definidos, por vezes, coincidindo com limites políticos de municípios, caracterizados pela ocorrência de patrimônio geológico, geomorfológico e/ou pedológico de relevância (incluindo as águas superficiais e subterrâneas), associado a uma estratégia de desenvolvimento sustentável, o que inclui ainda estratégias de gestão territorial.

Independentemente de sua região de ocorrência e atuação, um geoparque deve realizar a gestão integrada da geodiversidade com outros elementos patrimoniais naturais (biodiversidade) e culturais, com o objetivo de conservar e gerir o(s) patrimônio(s), incluindo, obrigatoriamente, as populações locais, possibilitando melhores condições de vida para as famílias que residem, sobretudo, nas proximidades dos geossítios, objetivando alcançar preceitos básicos da sustentabilidade (MOURA-FÉ, 2015).

Basicamente deve possuir um determinado conjunto de geossítios de importância internacional, nacional e/ou regional, que permitam contar e aprender a história geológica da região (NASCIMENTO et al., 2008). Lembrando que geossítios são locais de relevante geodiversidade, com significativo valor científico, educacional e/ou turístico e que devem também dar destaque à proteção e divulgação dos valores arqueológicos, ecológicos, históricos e culturais de uma região.

Nesse contexto, o GeoPark Araripe, primeiro geoparque das Américas e do hemisfério sul com selo da UNESCO e componente da Rede Global de Geoparques (Global Geoparks Network - GGN), foi criado em setembro de 2006, instituído pelo Governo Estadual do Ceará em parceria com a Universidade Regional do Cariri-URCA (HERZOG et al., 2008). Situado na região sul do Ceará, Nordeste do Brasil (Figura 1), no contexto geológico da bacia sedimentar do Araripe e geomorfológico da chapada do Araripe (MOURA-FÉ, 2016), mais especificamente em 06 (seis) municípios: Barbalha, Crato, Juazeiro do Norte, Missão Velha, Nova Olinda e Santana do Cariri, o chamado "território do GeoPark Araripe". 
Diagnóstico da relação entre a comunidade e o Geopark Araripe: geossítios colina do Horto e Pontal da Santa Cruz, Região Metropolitana do Cariri (RMC),

Figura 1 - Mapa do território do GeoPark Araripe, região sul do Ceará, com indicação dos geossítios abertos para visitação

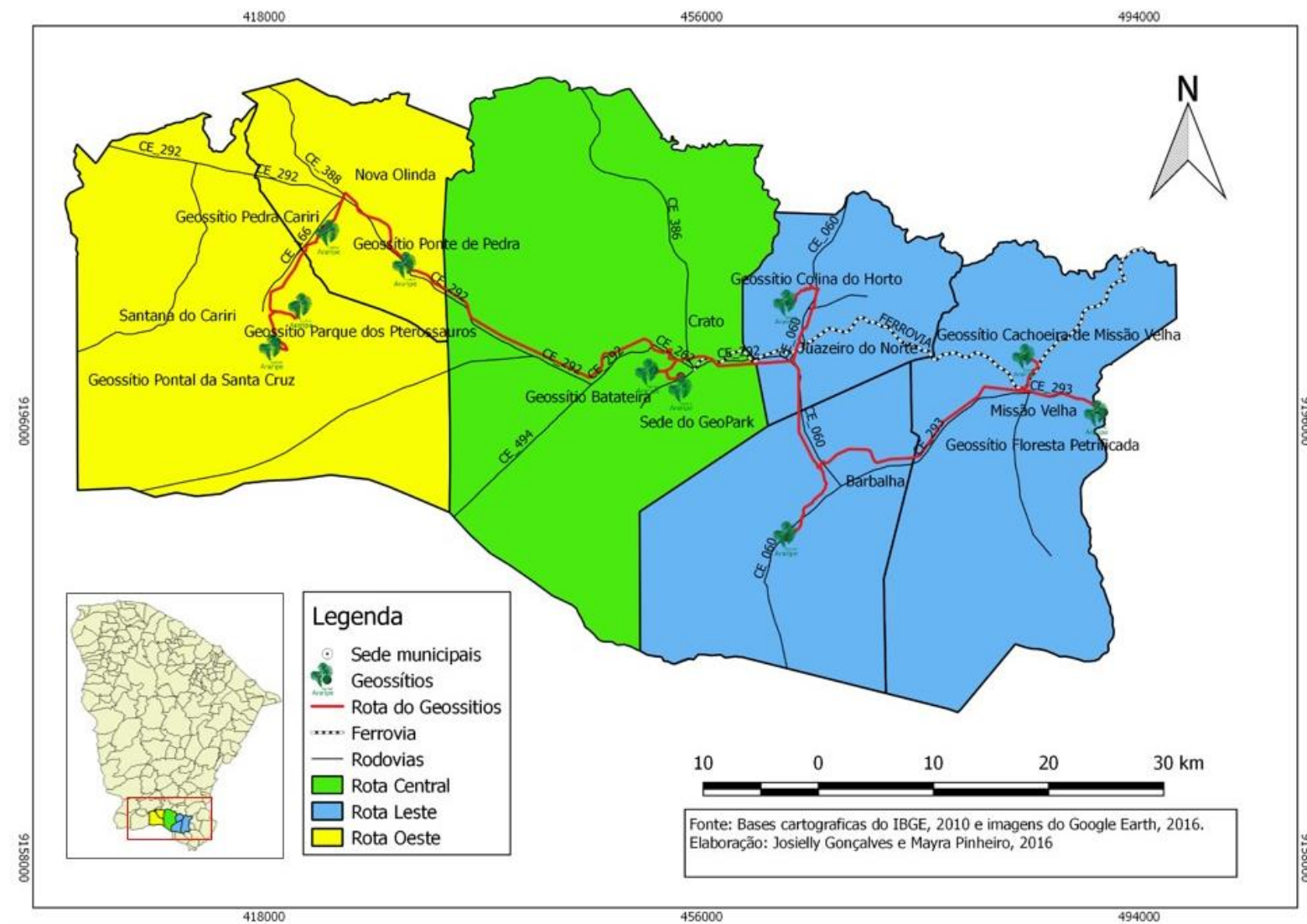

Fonte: Moura-Fé et al. (2017).

Esta área é considerada como detentora de não apenas um, mas dois worldclass fossil Konservat Lagestätten, em referência às duas importantes unidades fossilíferas que ali afloram: Membro Crato (VIANA; NEUMANN, 2002) e membro Romualdo (KELLNER, 2002) da Formação Santana. Os fósseis preservados nas jazidas da bacia sedimentar do Araripe são notáveis por sua abundância, diversidade e excepcional estado de conservação (HERZOG et al., 2008).

O GeoPark Araripe possui atualmente 9 (nove) geossítios abertos para visitação e tem como objetivos fundamentais: 1) a promoção da conservação do seu patrimônio natural (com ênfase na geodiversidade e considerando a biodiversidade) e cultural, em consonância com; 2) o desenvolvimento socioeconômico sustentável das comunidades locais, a priori, aquelas situadas próximas aos geossítios, através 
da geoeducação e do geoturismo, objetivando a identificação, aproximação e cogestão desses espaços (MOURA-FÉ, 2016), o que implicaria, por fim, em uma relação de conhecimento, cuidado e gestão por parte da comunidade em relação a um determinado geossítio.

Com base nesse segundo e importante objetivo básico, este artigo objetivou realizar um diagnóstico da relação entre as comunidades do Horto e do Pontal de Santa Cruz e os geossítios do GeoPark Araripe situados no seu entorno: geossítio Colina do Horto, em Juazeiro do Norte, e geossítio Pontal de Santa Cruz, em Santana do Cariri, RMC.

\section{MATERIAL E MÉTODOS}

O roteiro metodológico desenvolvido para buscar o supracitado objetivo é de abordagem qualitativa, sendo compartimentado em duas linhas: 1) embasamento teórico-conceitual, que tratou do estudo, análise e abordagem do conceito de geodiversidade e suas temáticas relacionadas, com ênfase nos conceitos de geoparques e geossítios; além de patrimônio, patrimônio natural e geoconservação; passando pela abordagem da relação das comunidades locais e suas sustentabilidades mútuas, com ênfase em dois geossitios; 2) contingente técnicocientífico, por sua vez, subdividido em etapas imbricadas, inter-relacionadas e, por vezes, cíclicas, a saber: gabinete, campo e laboratório.

Inicialmente, em gabinete, realizou-se um levantamento bibliográfico em obras relevantes e atuais presentes nas literaturas científicas nacional e internacional que tratam das temáticas discutidas, com ênfase em estratégias de geoconservação voltadas para as comunidades da área de estudo. Nesse aspecto, foi realizado uma caracterização da geodiversidade no contexto territorial do GeoPark Araripe, mais precisamente nos municípios de Juazeiro do Norte e Santana do Cariri e em dois geossítios situados em seus territórios.

As análises feitas a partir dessa etapa, bem como a partir do conhecimento prévio dos pesquisadores sobre a área de estudo, embasaram a elaboração de um 
questionário composto de interesse socioeconômico e de interesse geopatrimonial, baseados em Castro, Mansur e Carvalho (2015).

A etapa seguinte está relacionada aos trabalhos de campo, realizados em diversos períodos, com ênfase nos geossítios mencionados e suas comunidades associadas, objetivando tanto aprimorar a caracterização da geodiversidade (e temáticas relacionadas) dos locais quanto a aplicação dos questionários através de entrevistas. As entrevistas foram realizadas na comunidade do Pontal da Santa Cruz em agosto de 2016, com o objetivo de conhecer os moradores locais e quais eram seus entendimentos sobre assuntos relacionados os geossítios e as ações do GeoPark Araripe, bem como traçar um perfil socioeconômico dos entrevistados.

O questionário aplicado na comunidade do Horto (Anexo A) em agosto de 2016 é composto por 20 (vinte) questões, sendo que 13 (treze) de interesse socioeconômico e 07 (sete) de ordem geopatrimonial. Por sua vez, o questionário aplicado na comunidade do Pontal de Santa Cruz (Anexo B) é composto por 21 (vinte e uma) questões, sendo 13 (treze) de interesse socioeconômico e 08 (oito) de interesse geopatrimonial.

Por meio das questões socioeconômicas objetivou-se conhecer a comunidade, ao incluir na entrevista questões de gênero, idade, grau de escolaridade, religião, entre outros. Também foram abordadas questões referentes às pessoas e seus lugares. Por sua vez, as questões geopatrimoniais estavam direcionadas ao GeoPark Araripe e seus geossítios, a importância dos mesmos e o grau de conhecimento sobre patrimônio por parte das pessoas entrevistadas. As perguntas buscaram compor um quadro que pudesse nos aproximar dos principais pontos de carência de informação e conhecimento, e o nível de envolvimento social, cultural e econômico da população local com a geodiversidade desses geossítios, dentre outros aspectos.

Os dados adquiridos em campo, bem como os preceitos adquiridos nas etapas metodológicas de gabinete foram tratados conjuntamente em laboratório, com a tabulação dos dados, elaboração de gráficos, quadros e mapas, recursos importantes para realizar a discussão dos resultados. As análises oriundas desse roteiro metodológico subsidiaram uma nova etapa de análises em gabinete, cujos resultados serão apresentados a partir do próximo item. 


\section{RESULTADOS E DISCUSSÃO}

\subsection{GEOSSÍTIOS E SEUS PATRIMÔNIOS}

Inserido no município com a maior taxa de urbanização da RMC (BANDEIRA et al., 2016; GURGEL, 2012; NASCIMENTO; CHACON, 2016), o Geossítio Colina do Horto apresenta significativos valores científico e didático/educação e treinamento (MOCHIUTTI et al., 2012), ao passo que, por exemplo, pode-se realizar um trabalho de campo com estudantes da graduação em Geografia (Figura 2a) e abordar o ciclo das rochas. Localizado a $3 \mathrm{~km}$ da sede de Juazeiro do Norte, este geossítio representa o modelado mais significativo do município, erigido sobre as litologias mais antigas da região, as quais compõem o embasamento cristalino, com idade aproximada de $650 \mathrm{Ma}$ (CEARÁ, 2012).

Por outro lado, em relação ao valor cultural/espiritual (MOCHIUTTI et al., 2012), no topo da Colina do Horto e ao longo da trilha do Santo Sepulcro, podem ser encontradas pedras empilhadas por romeiros, inclusive em placas do GeoPark Araripe (Figura 2b), em sinal de devoção, agradecimento ou renovação dos votos de fé, o que inclui o retorno à cidade no ano seguinte. Ainda nessa trilha, que segundo historiadores, o Padre Cícero realizava caminhadas regulares, há uma rocha fragmentada por intemperismo físico (termoclastia) (Figura 2c), chamada de "Pedra do Pecado", cuja estreita passagem, se realizada pelo(a) romeiro(a), daria a absolvição dos seus pecados.

Ainda nesse geossítio, há fragmentos bem conservados do "Muro da Resistência" (Figura 2d), construção que remonta ao processo de emancipação de Juazeiro do Norte em relação ao município do Crato no começo do século XX, marcado por conflitos armados (LIRA NETO, 2009). Sobretudo por conta da história e da religiosidade em torno da figura do Padre Cícero Romão (Figura 2e), é o principal local de visitação turística de toda a região.

Por sua vez, o geossítio Pontal da Santa Cruz (Santana do Cariri) apresenta importante valor cultural e histórico (MOCHIUTTI et al., 2012), concentrados no 
Diagnóstico da relação entre a comunidade e o Geopark Araripe: geossítios colina do Horto e Pontal da Santa Cruz, Região Metropolitana do Cariri (RMC),

mirante do Pontal de Santa Cruz (Figura 3a), um fator identitário para todo o município, sobretudo para a comunidade homônima, residente, na sua maioria, no sopé do relevo elevado que caracteriza o geossítio.

Figura 2 - Mosaico de fotos do Geossítio Colina do Horto (Juazeiro do Norte, RMC, Ceará)



A - Trabalho de campo de alunos do curso de Geografia da URCA.



C - Pedra do Pecado, trilha do Santo Sepulcro.

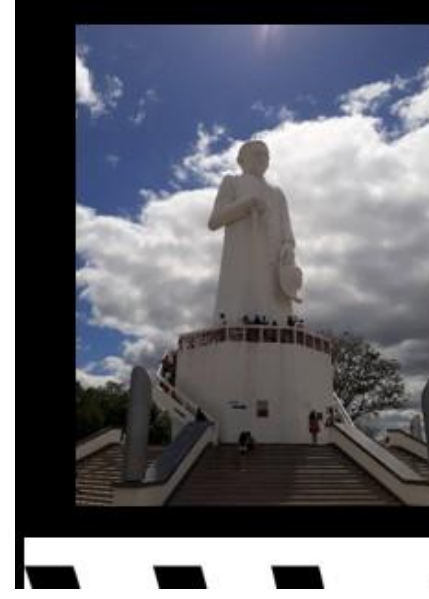

E - Estátua

do Padre

Cícero, cartão-

postal do

Cariri

cearense.

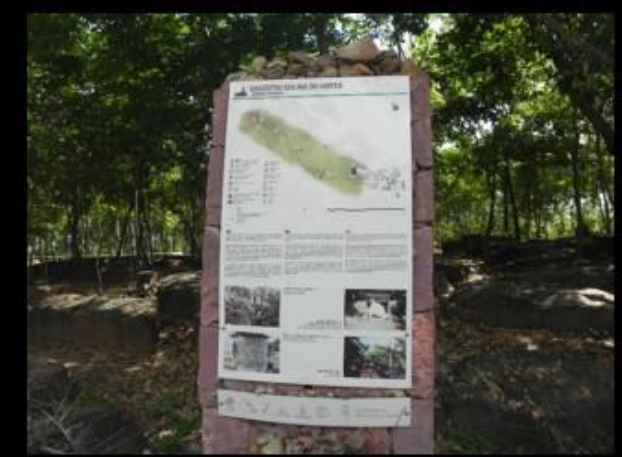

B - Placa de informação turística/educacional com pedras colocadas pelos romeiros.

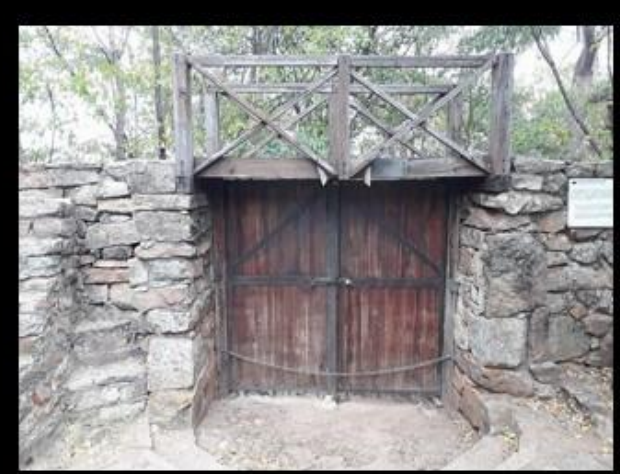

D - Muro da Resistência, resquício da Sedição de Juazeiro.
Fotos:

A: Marcelo Martins (Mai, 2016);

B, C: Marcelo Martins (Mar, 2016);

D: Marcelo Martins (Set, 2017);

E: Marcelo Martins (Mar, 2018)

Fonte: elaborado pelos autores (2018). 
Diagnóstico da relação entre a comunidade e o

Geopark Araripe: geossítios colina do Horto e Pontal da

Santa Cruz, Região Metropolitana do Cariri (RMC),

Ceará

Figura 3 - Mosaico de fotos do Geossítio Pontal de Santa Cruz (Santana do Cariri,

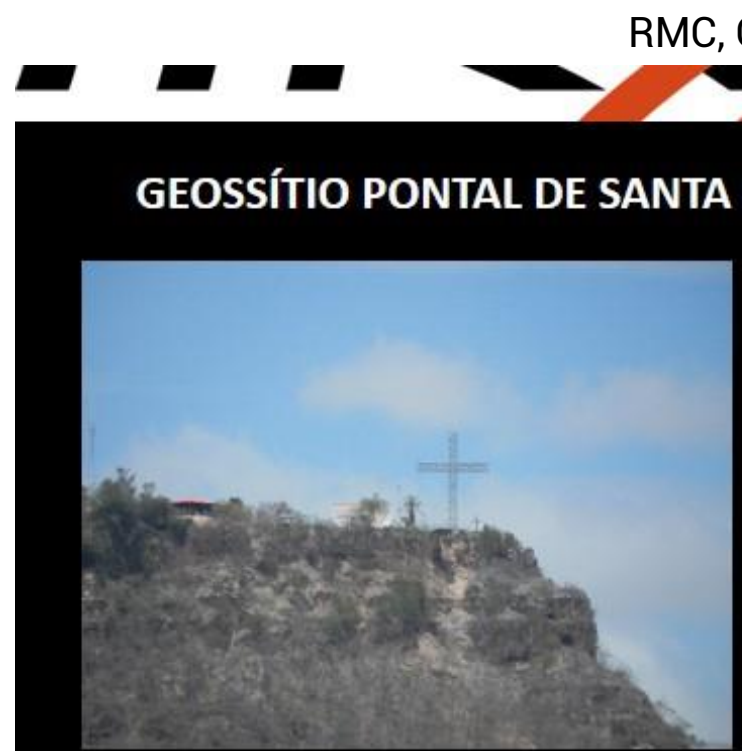

A - Vista do Pontal de Santa Cruz e suas cruzes.
B - Vista geral da maior parte das casas da comunidade do Pontal.

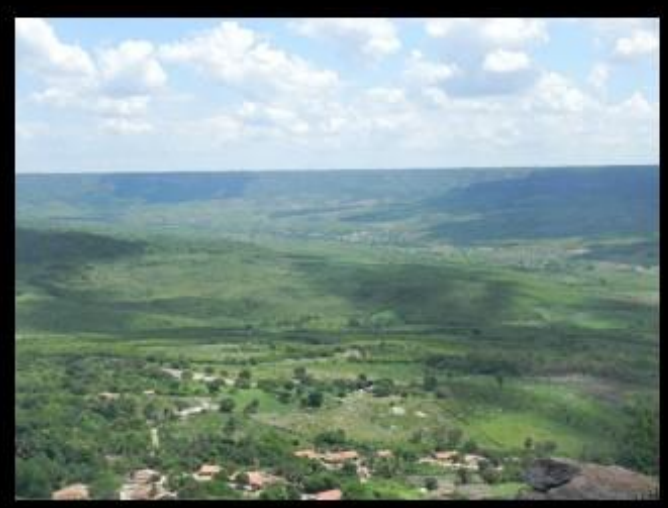

D - Panorama da encosta da chapada do Araripe em Santana do Cariri. No topo das linhas de ravinamento há diversas nascentes.

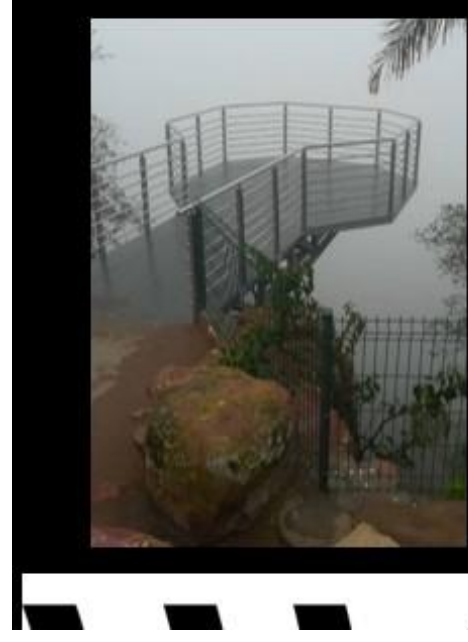

E - Estrutura metálica que potencializa a visão da paisagem no geossítio. A: Marcelo Martins (Set, 2017); B: Marcelo Martins (Mai, 2016); Ce D: Marcelo Martins (Mar, 2016); E: Marcelo Martins (Mar, 2018)

NÚCLEO DE ESTUDOS

INTEGRADOS EM GEOMORFOLOGIA GEODIVERSIDADE E PATRIMÔNIO

Fonte: elaborado pelos autores (2018). 
Também apresenta considerável valor funcional ao ser dotado de uma mata subúmida, mantida pelas condições climáticas locais mais amenas, relacionadas ao fator da altitude, vegetação esta que apresenta funções ecossistêmicas diferentes da mata da caatinga, majoritária no entorno topograficamente mais rebaixado, onde fica a comunidade homônima (Figura 3b).

Este Geossítio, do tipo geomorfológico, foi modelado na porção superior da escarpa da chapada do Araripe. A Formação Exu é a mais jovem da bacia do Araripe (90 Ma) sendo formada por arenitos coesos, atuando como uma capa resistente da chapada (Figura 3c) (ASSINE, 2007). Hidrogeologicamente, é considerado permeável, absorvendo facilmente as águas das chuvas, as quais acumulam-se nas camadas mais baixas, dando origem às nascentes que permeiam diversos trechos da encosta da chapada e visíveis a partir do mirante do Geossítio (Figura 3d).

Assim, no local há um dos melhores mirantes de toda a região (Figura 3e), que permite a visão panorâmica de parte da Chapada do Araripe, do vale do rio Cariús e da sede do município de Santana do Cariri, permitindo assim diversas formas de interpretação da paisagem.

\subsubsection{Geossítio Colina do Horto: fé e desconhecimento}

Adotando os questionários realizados como instrumentos de pesquisa, os quais permitiram, de forma simples e em associação com dados coletados diretamente em campo, a aquisição de informações relevantes, apresentando ora singularidades ora semelhanças dos geossítios e suas respectivas comunidades associadas.

Juazeiro do Norte é um município instalado em 22/07/1911, que abrange uma área de $248,833 \mathrm{~km}^{2}$, em meio ao domínio morfoclimático do semiárido do Nordeste brasileiro (AB'SABER, 2003). Segundo dados do IBGE (2010) a população municipal alcançava os 249.939 habitantes, sendo subdividida entre a população rural e urbana em 9.811 e 240.128 habitantes, respectivamente.

Assim, o município de Juazeiro do Norte, segundo maior em população do Ceará, maior cidade do território do GeoPark Araripe e mais importante município da $\mathrm{RMC}$, apresenta a forte religiosidade ligada à fé no padre Cicero, figura $\mathrm{p}$ de total 
importância na criação do município, cuja figura histórica é fortemente identificada com a Colina do Horto.

Nesse contexto, 64 (sessenta e quatro) pessoas foram entrevistadas na comunidade do Horto (Tabela 1), as quais apresentam, em sua maior parte, baixos índices de escolaridade (Gráfico 1).

Tabela 1 - Faixa etária e gênero das pessoas entrevistadas na comunidade do Horto

\begin{tabular}{l|c|c|c}
\multicolumn{1}{c|}{ FAIXA ETÁRIA } & HOMENS & MULHERES & TOTAL \\
\hline De 15 a 18 anos & $\mathbf{0 0}$ & $\mathbf{0 3}$ & $\mathbf{0 3}$ \\
\hline Entre 19 e 25 anos & $\mathbf{0 2}$ & $\mathbf{0 5}$ & $\mathbf{0 7}$ \\
\hline Entre 26 a 35 anos & $\mathbf{0 4}$ & $\mathbf{0 9}$ & $\mathbf{1 3}$ \\
\hline Entre 36 a 49 & $\mathbf{0 8}$ & $\mathbf{0 8}$ & $\mathbf{1 6}$ \\
\hline Entre 49 e 69 & $\mathbf{0 9}$ & $\mathbf{0 9}$ & $\mathbf{1 8}$ \\
\hline Mais de 70 & $\mathbf{0 3}$ & $\mathbf{0 4}$ & $\mathbf{0 7}$ \\
\hline Total & $\mathbf{2 6}$ & $\mathbf{3 8}$ & 64
\end{tabular}

Fonte: elaborado pelos autores (2018).

Gráfico 1 - Grau de escolaridade das pessoas entrevistadas na comunidade do Horto

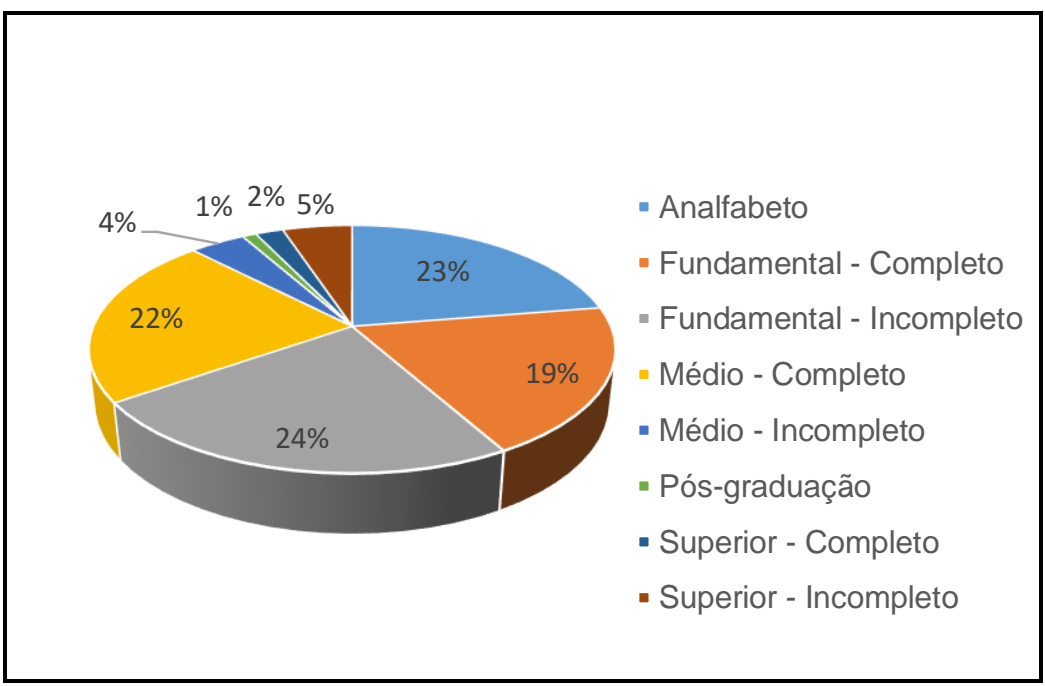

Fonte: elaborado pelos autores (2018).

Esses dados socioeconômicos, embora pouco representativos estatisticamente para a comunidade como um todo, demonstram, pelo menos, que a população entrevistada caracterizou-se como razoavelmente equilibrada entre os sexos e composta, em sua maior parte, de adultos, o que torna os dados referentes à 
questão escolar ainda mais preocupantes, ao passo que, ao se inserirem no mercado de trabalho, algo esperado para os adultos da comunidade, dificilmente se tem estímulo para retomar os estudos.

Tais resultados podem ser ainda mais significativo ao considerar que algumas pessoas se recusaram a responder o questionário por julgar que não entendiam do assunto para poder responder.

A maior parte dos entrevistados foram comerciantes (vide dados específicos na Tabela 2), que passaram a morar no local influenciados pela devoção do Padre Cicero (o que explica o fato de $99 \%$ dos entrevistados se declararem católicos) e, claro, também pela busca de renda, sendo oriundos de outros estados da região Nordeste, sendo Pernambuco o estado mais citado.

Tabela 2 - Principal ocupação econômica das pessoas entrevistadas na comunidade do Horto

\begin{tabular}{l|c}
\multicolumn{1}{c}{ PRINCIPAL OCUPAÇÃO ECONÔMICA } & NÚMERO DE PESSOAS \\
$\begin{array}{l}\text { Trabalhador sem vínculo (comerciantes, } \\
\text { sobretudo) }\end{array}$ & 31 \\
\hline Funcionário público & 02 \\
\hline Estudante & 07 \\
\hline Desempregado & 06 \\
\hline Aposentado & 14 \\
\hline Dona de Casa & 04 \\
\hline Total & 64
\end{tabular}

Fonte: elaborado pelos autores (2018).

Feita essa breve caracterização socioeconômica, pode-se tratar dos aspectos relacionados ao GeoPark Araripe e o geossítio Colina do Horto. De maneira resumida, os dados podem ser sintetizados na palavra: "desconhecimento".

Quase $1 / 4$ dos entrevistados declarou nunca ter visitado um dos geossítios do GeoPark Araripe (Gráfico 2), alegando conhecer o GeoPark apenas nas notícias que viam na televisão, embora morassem nas proximidades de um deles. Outro aspecto preocupante é que a maioria das pessoas também não sabia por que aquela área era considerada um geossítio (Gráfico 3), sem se dar conta que eles são parte importante dos objetivos do projeto ao morarem próximos a um dos geossítios. 
Entre as questões de interesse geopatrimonial, buscou-se compreender o que essa comunidade entende como patrimônio. Desta forma, perguntou-se para os entrevistados o que eles consideravam importante, que merecia ser protegido e preservado. Assim, foi apresentado aos entrevistados palavras diversas. Quando a resposta era afirmativa, a palavra era assinalada.

Gráficos 2 e 3 - Respostas das pessoas entrevistadas na comunidade do Horto sobre terem visitado algum Geossítio do GeoPark Araripe e sobre a razão do Horto ser um Geossítio

Visitaram um Geossitio

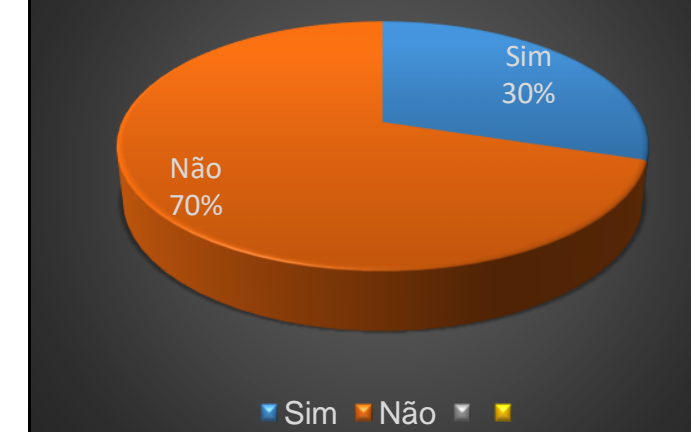

\section{Sabem o motivo do lugar} ser um Geossítio?



Fonte: elaborado pelos autores (2018).

Essas palavras envolviam categorias diferentes de patrimônios como: cultural e natural, de cunho histórico, artístico, científico, arquitetônico, entre outras. Com base em Castro et al. (2015), o conjunto foi formado com 16 palavras, nesta ordem: casa, osso, rua, pedra, artesanato, fóssil, comida, homem, jacaré, planeta Terra, dança, prédio antigo, flor, lenda / história, árvore, DNA e novela.

Pode-se aferir que, quanto mais itens são considerados como patrimônio, mais abrangente será a percepção patrimonial da população entrevistada. Os resultados podem ser observados no Gráfico 4, e, assim, pode-se ver que mesmo com pouco entendimento do assunto, as pessoas entendem o que é patrimônio, entendem como tudo aquilo que tem um valor e merece ser preservado para as futuras gerações. 


\subsubsection{A Comunidade e o Geossítio Pontal de Santa Cruz: crenças e ausências}

Santana do Cariri é uma marca histórica no povoamento da chapada do Araripe e do vale do Cariri, o qual ocorreu a partir da segunda metade do século XVII, sendo uma das primeiras vilas a se emanciparam, mais precisamente, em 1885, se inserindo na primeira etapa da história econômica social e política da região do Cariri cearense. Inicialmente chamada de "Brejo Grande", a localidade era habitada pela tribo indígena denominada de Buxixés. Suas origens remontam ao final do século XVIII, quando colonizadores procedentes da Casa da Torre, na Bahia, pediram e obtiveram terras nas margens do riacho Brejo Grande, hoje rio Cariús (CEARÁ, 2012).

Gráfico 4 - Respostas das pessoas entrevistadas na comunidade do Horto sobre o entendimento do que é patrimônio



Fonte: elaborado pelos autores (2018).

Diante de específicas condições naturalmente favoráveis à pecuária e, sobretudo, à agricultura, houve rápido desenvolvimento da localidade, atraindo novos moradores que, dentre outras coisas, ergueram a capela em louvor à Senhora Santana, local da atual Matriz (CEARÁ, 2012).

Atualmente, o município é conhecido mundialmente por possuir um patrimônio fossilífero excepcional, embutido em uma rica história geológica que 
remonta ao episódio de separação dos continentes sul-americano e africano, um patrimônio natural (geodiversidade) que motivou a criação do Museu de Paleontologia da URCA e dos geossítios Parque dos Pterossauros e Pontal de Santa Cruz, equipamentos do GeoPark Araripe que atraem, anualmente, mais visitantes do que a quantidade de moradores existente no município.

Santana do Cariri destaca-se, também, pela produção do artesanato com a temática paleontológica, com a reutilização de materiais como: garrafas pet, latinhas de refrigerante ou até mesmo o rejeito das lavras de calcário. Todos esses fatores contribuem para que Santana do Cariri tenha recebido o título de capital cearense da Paleontologia, do Governo do Estado do Ceará.

Nesse contexto, 70 (setenta) pessoas foram entrevistadas na comunidade do Pontal de Santa Cruz (Tabela 3), 98\% delas, católicas, evidenciando que a comunidade ainda está muito associada aos preceitos religiosos que deram, por exemplo, o nome e a origem do povoado de Pontal da Santa Cruz. As pessoas entrevistas apresentaram, em sua maior parte, baixos índices de escolaridade (Gráfico 5).

Tabela 3 - Faixa etária e gênero das pessoas entrevistadas na comunidade do Pontal de Santa Cruz

\begin{tabular}{l|c|c|c}
\multicolumn{1}{c|}{ Faixa Etária } & Homens & Mulheres & Total \\
\hline De 15 a 18 anos & $\mathbf{0 0}$ & $\mathbf{0 0}$ & $\mathbf{0 0}$ \\
\hline Entre 19 e 25 anos & $\mathbf{0 3}$ & $\mathbf{0 4}$ & $\mathbf{0 7}$ \\
\hline Entre 26 a 35 anos & $\mathbf{0 6}$ & $\mathbf{0 8}$ & $\mathbf{1 4}$ \\
\hline Entre 36 a 49 & $\mathbf{0 4}$ & $\mathbf{0 9}$ & $\mathbf{1 3}$ \\
\hline Entre 49 e 69 & $\mathbf{0 8}$ & $\mathbf{1 7}$ & $\mathbf{2 5}$ \\
\hline Mais de 70 & $\mathbf{0 7}$ & $\mathbf{0 4}$ & $\mathbf{1 1}$ \\
\hline Total & $\mathbf{2 8}$ & $\mathbf{4 2}$ & $\mathbf{7 0}$
\end{tabular}

Fonte: elaborado pelos autores (2018). 
Gráfico 5 - Grau de escolaridade das pessoas entrevistadas na comunidade do Pontal de Santa Cruz

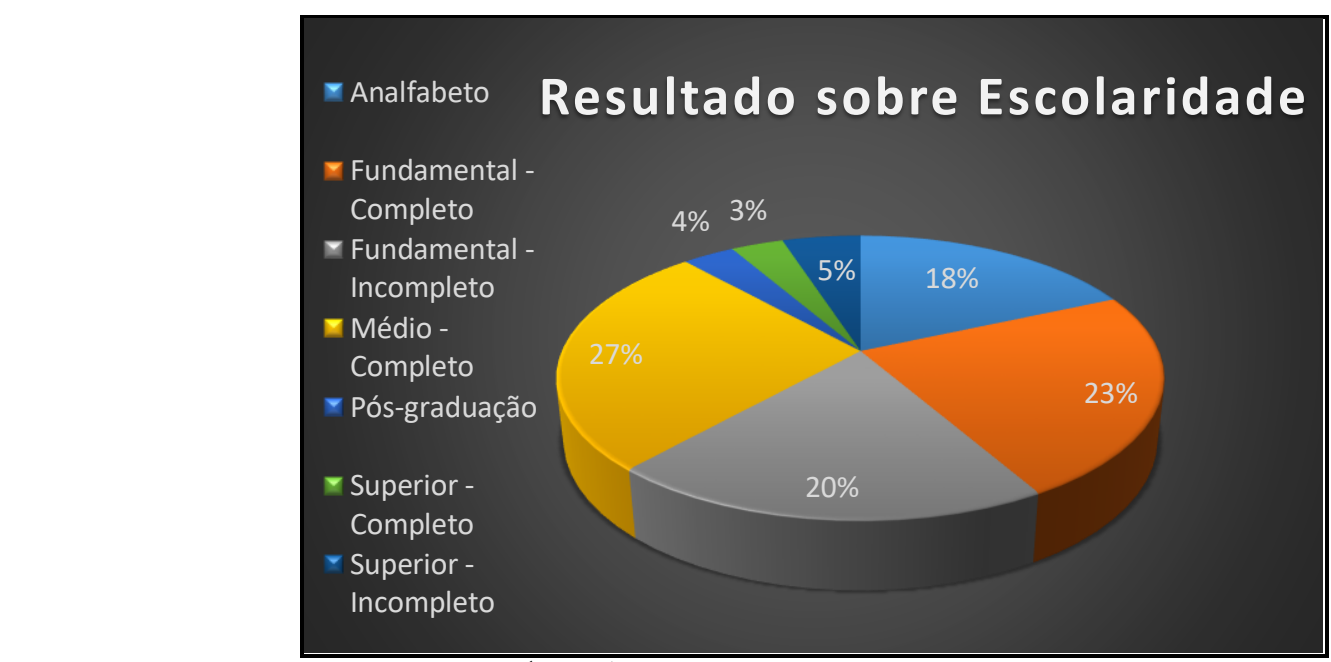

Fonte: elaborado pelos autores (2018).

De conhecimento popular, o cruzeiro colocado no topo do mirante do geossítio Pontal de Santa Cruz, referência identitária para a comunidade, foi ali fincado graças à crença da população na existência de criaturas místicas, que assombrariam a região. As assombrações, segundo relatos dos moradores, se manifestam, sobretudo, através de uivos, o que pode ser explicado pelas características ruiniformes dos arenitos que afloram na encosta da chapada do Araripe, que favorecem os "assobios" na passagem dos ventos pelas rochas.

A instalação do cruzeiro no Pontal da Santa Cruz e suas lendas, deram início à exploração turística da área, hoje composta pelo cruzeiro citado, e uma outra estrutura metálica de maiores proporções em forma de cruz, bem como uma capela, um restaurante de administração privada, associando, assim, o turismo religioso ao ecoturismo e geoturismo na localidade.

No tocante específico ao geopatrimônio, o interesse e/ou conhecimento sobre os aspectos da geodiversidade são poucos, sendo mais relevante quando se fala do Museu de Paleontologia da URCA, localizado no centro da cidade de Santana do Cariri, local de constante visita de profissionais e estudiosos de geociências, e bastante conhecido pela comunidade, tanto o equipamento, quanto seu principal atrativo, os fósseis (Gráficos 6 e 7). 
Gráficos 6 e 7 - Respostas das pessoas entrevistadas na comunidade do

Pontal de Santa Cruz a respeito do Museu de Paleontologia e os fósseis



Fonte: elaborado pelos autores (2018).

Por outro lado, conforme o Gráfico 8, quase 70\% dos entrevistados disse saber o que é o GeoPark Araripe, todavia, mais de $60 \%$ das pessoas disse não saber o que é um geossítio (Gráfico 9).

Um fator que amplia o paradoxo é o fato do município de Santana do Cariri possuir dois geossítios: o Parque dos Pterossauros e o Pontal de Santa Cruz. Talvez, a imprensa os aproxime do que seja o GeoPark, através das diversas matérias veiculadas, mas o próprio GeoPark não consiga ampliar esse entendimento, levando para a comunidade esse fundamental aspecto que são os geossítios, bem como, os usos possíveis e sua importância científica, por exemplo. Possibilidade reforçada pelo Gráfico 10.

Gráfico 8 e 9 - Respostas das pessoas entrevistadas na comunidade do Pontal de Santa Cruz sobre se sabem o que é GeoPark Araripe e o que são geossítios

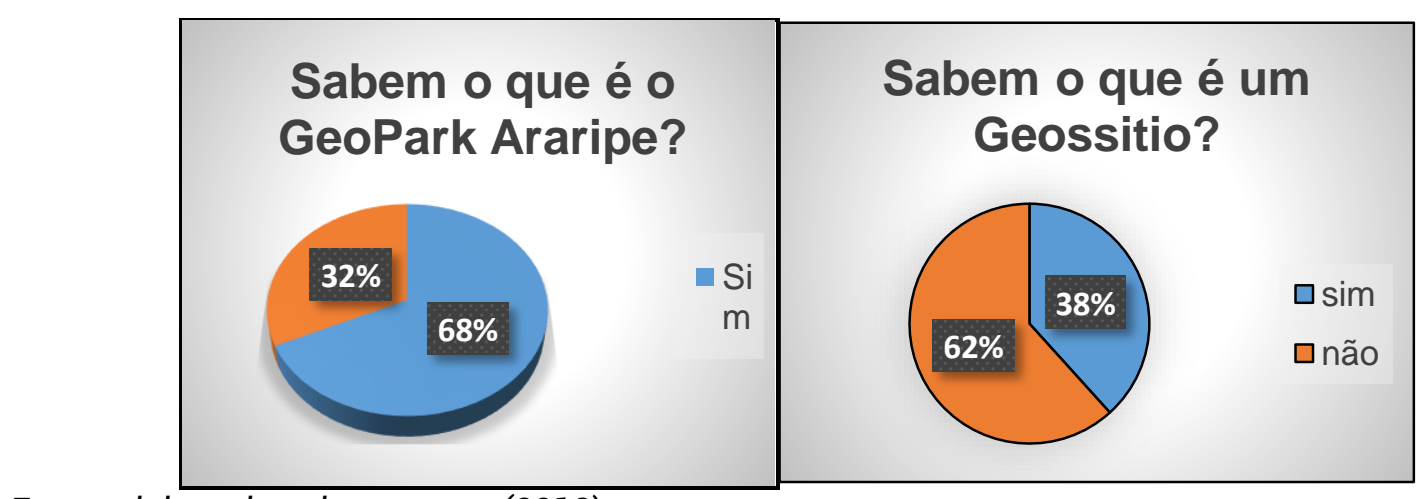

Fonte: elaborado pelos autores (2018). 
Gráfico 10 - Respostas das pessoas entrevistadas na comunidade do Pontal de Santa Cruz sobre o Geossítio Pontal de Santa Cruz

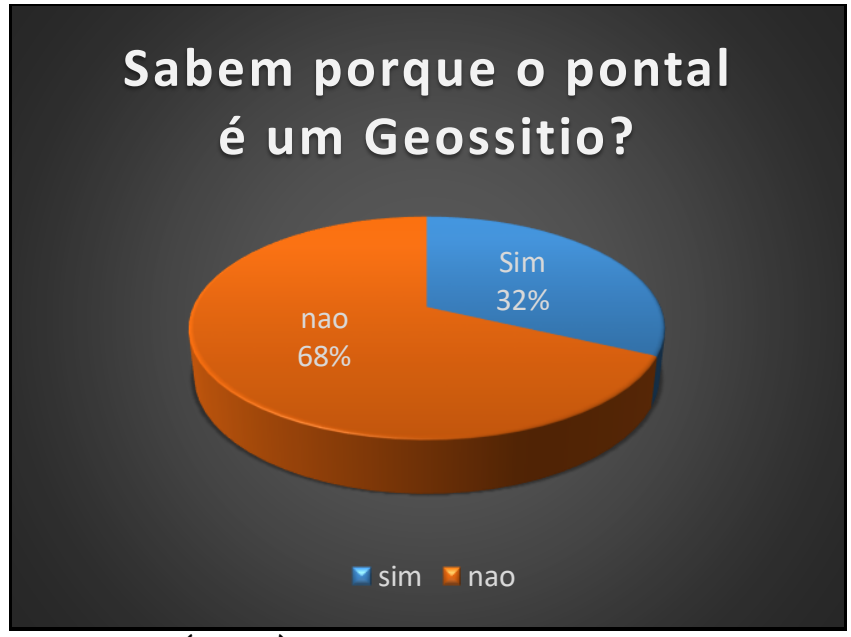

Fonte: elaborado pelos autores (2018).

Essa diferença entre o conhecimento sobre o GeoPark Araripe / geossítios e o Museu de Paleontologia / fósseis pode ser explicada pelo tempo de atuação de um em relação ao outro, o GeoPark tem 12 anos de criação, o Museu de Paleontologia tem mais de 30 anos de fundação. Por outro lado, uma maior proximidade e a implementação de projetos mais regulares na comunidade por parte do GeoPark, provavelmente, deveriam dirimir esse distanciamento.

$\mathrm{Na}$ comunidade do Pontal da Santa Cruz, conforme relatos dos entrevistas, não existia, até então, nenhum tipo de ação ou projeto com escopo na divulgação do conhecimento e conservação da geodiversidade local, ou mesmo com foco na geoeducação ou geoturismo, que pudessem se agregar de forma mais perene, e por conseguinte, eficaz, ao cotidiano da comunidade.

Por fim, assim como na comunidade do Horto, questões de interesse geopatrimonial foram aplicadas na comunidade do Pontal de Santa Cruz e sobre seu entendimento do que seja patrimônio, com a mesma metodologia, tendo Castro et al. (2015) como base. Os resultados podem ser observados no Gráfico 11, apresentando bons indicadores do conhecimento sobre patrimônio. 
Gráfico 11 - Respostas das pessoas entrevistadas na comunidade do Pontal de Santa Cruz sobre o entendimento do que é patrimônio

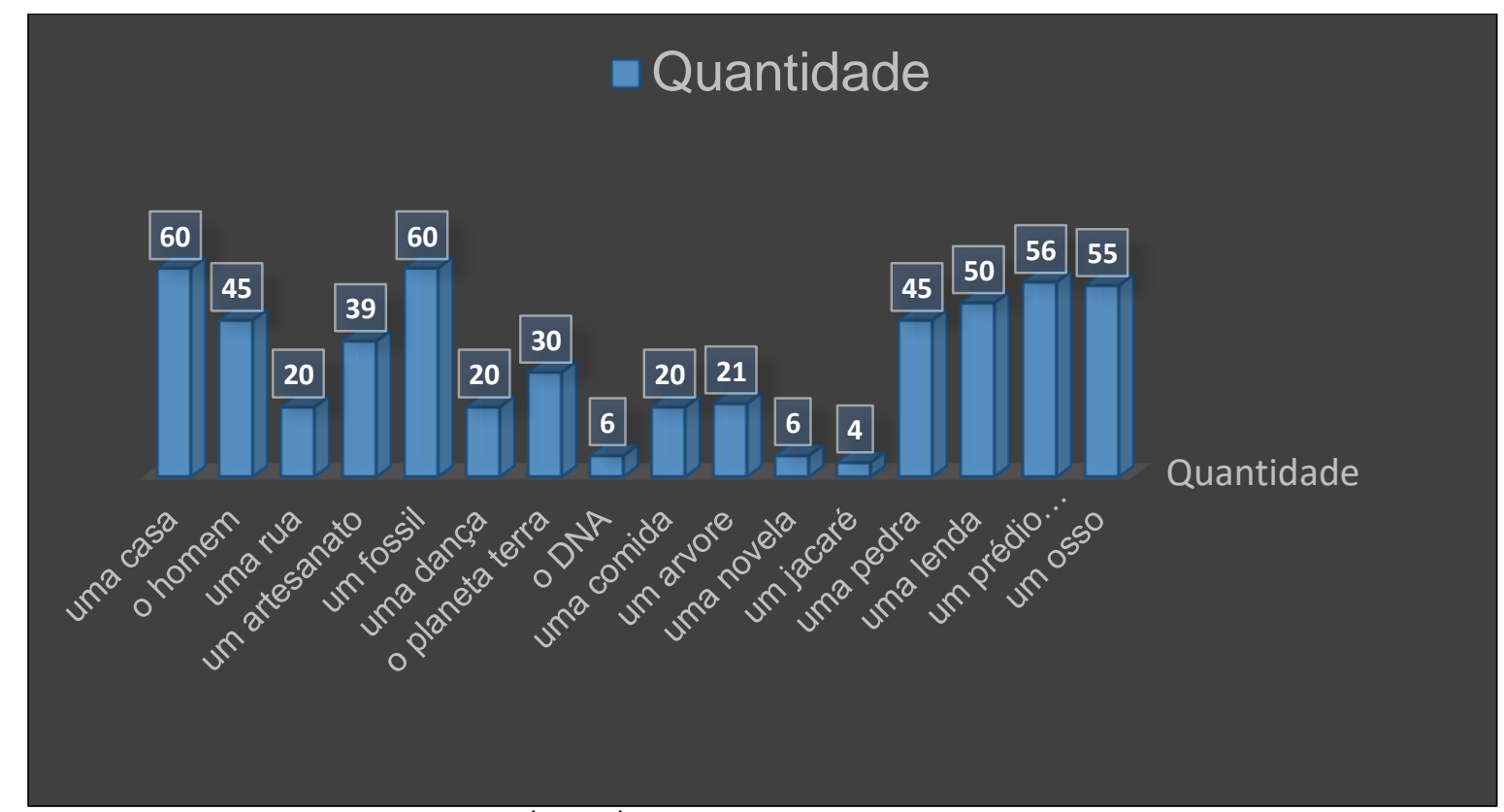

Fonte: elaborado pelos autores (2018).

\section{CONSIDERAÇÕES FINAIS}

Com a análise dos dados coletados pode-se realizar um diagnóstico básico da relação das comunidades do Pontal de Santa Cruz, em Santana do Cariri, e do Horto, em Juazeiro do Norte, com o GeoPark Araripe. A partir da parcela entrevistada das comunidades, pode-se, senão convictamente tecer um panorama detalhado, identificar elementos que podem contribuir para a melhoria dessa relação.

Em que pese o tempo de atuação do importante projeto do GeoPark Araripe, o qual vem dando significativa visibilidade para questões conservacionistas, incluindo o conhecimento e a valorização de parte do patrimônio natural do Cariri cearense; há uma clara carência de conhecimentos que os moradores dessas comunidades apresentam, as quais passam pelos objetivos do projeto, o que são os geossítios e como pode se dar a relação entre esses locais e as comunidades.

E é exatamente no entendimento de como deve ser essa relação entre a comunidade e o GeoPark Araripe, mormente através dos seus geossítios, que essas lacunas podem ser preenchidas paulatina e sustentavelmente. Projetos de educação 
ambiental e/ou patrimonial, temporalmente mais regulares, com escopos voltados para as especificidades dos lugares e das comunidades. Considerar as singularidades e estabelecer um contato mais regular são dimensões imprescindíveis para se realizar esse trabalho que é, essencialmente, educativo.

Por outro lado, dentro do conjunto de estratégias conservacionistas, também podem ser pensadas e planejadas conjuntamente, iniciativas de atividades socioeconômicas voltadas para a parcela da comunidade economicamente ativa. Tais atividades podem estar direta e indiretamente ligadas ao turismo sustentável e o geoturismo, as quais poderão trazer melhoria na qualidade de vida das pessoas e melhorar o receptivo turístico na região.

Em suma, a educação ambiental, a geoeducação, o turismos sustentável e o geoturismo, devidamente implantados nas comunidades tratadas aqui e nas outras existentes no território, poderão dirimir esse quadro de desconhecimento e distanciamento entre as comunidades e o GeoPark Araripe. Maior conhecimento e maior aproximação deverão levar, efetivamente, o GeoPark Araripe para o cotidiano das pessoas, aproximando-o de um dos seus objetivos básicos, o desenvolvimento sustentável das comunidades locais no seu território.

\section{REFERÊNCIAS}

AB'SABER, A. Os domínios de Natureza no Brasil - potencialidades paisagísticas. São Paulo: Ateliê editorial, 2003.

ASSINE, M. L. Bacia do Araripe. Boletim de Geociências da Petrobrás, v. 15, n. 2, p. 371-389, 2007.

BANDEIRA, A. P. N.; NUNES, P. H. S.; LIMA, M. G. S. Gerenciamento de riscos ambientais em municípios da Região Metropolitana do Cariri (Ceará). Ambiente \& Sociedade, v. 19, n. 04, p. 65-84, 2016.

CASTRO, A. R. S. F.; MANSUR, K. L.; CARVALHO, I. S. Diagnóstico da relação da comunidade com o patrimônio geológico por meio de instrumento de coleta de dados. Terra e Didática, v. 3, n. 11, p. 162-172, 2015.

CEARÁ. Lei Complementar $\mathbf{n}^{\circ} \mathbf{7 8}$, de 26 de junho de 2009. Dispõe sobre a criação da Região Metropolitana do Cariri, cria o Conselho de desenvolvimento e Integração e o fundo de Desenvolvimento e integração da Região Metropolitana do Cariri - FDMC, 
altera a composição de Microrregiões do Estado do Ceará e dá outras providências. Fortaleza, CE, 03 de julho de 2009.

CEARÁ. Geopark Araripe: histórias da Terra, do Meio Ambiente e da Cultura. CratoCE: Projeto Cidades do Ceará, 2012.

GURGEL, A. P. C. Entre serras e sertões nasce uma Região Metropolitana: o Crajubar-Ceará sob o ponto de vista de suas centralidades. DRd - Desenvolvimento Regional em Debate, v. 2, n. 2, p. 182-204, 2012.

HERZOG, A. et al. The UNESCO Araripe Geopark: a short story of the evolution of life, rocks and continentes. 2008.

INSTITUTO BRASILEIRO DE GEOGRAFIA E ESTATÍSTICA - IBGE. Resultados do Censo 2010. Diário Oficial da União, 4 de novembro de 2010.

KELLNER, A. W. A. Membro Romualdo da Formação Santana, Chapada do Araripe, CE. In: SCHOBBENHAUS, C. et al. Sítios Geológicos e Paleontológicos do Brasil. Brasília: DNPM/CPRM - SIGEP, 2002.

LIRA NETO. Padre Cícero: poder, fé e guerra no sertão. São Paulo: Companhia das Letras, 2009.

MOCHIUTTI, N. F.; GUIMARÃES, G. B.; MOREIRA, J. C.; LIMA, F. F.; FREITAS, F. I. Os valores da geodiversidade: geossítios do Geopark Araripe/CE. Anuário do Instituto de Geociências, v. 35, n. 1, p. 173-189, 2012.

MOURA-FÉ, M. M. GeoPark Araripe e a geodiversidade do sul do Estado do Ceará, Brasil. Revista de Geociências do Nordeste, v. 2, n. 1, p.28-37, 2016.

MOURA-FÉ, M. M. Geoturismo: uma proposta de turismo sustentável e conservacionista para a Região Nordeste do Brasil. Sociedade \& Natureza, Uberlândia-MG, v. 27, n. 1, p. 53-66, 2015.

MOURA-FÉ, M. M.; SILVA, J. V. M.; BRASIL, J. G. Geocultura: proposta de estudo da relação entre geodiversidade e cultura. In: PEREZ FILHO, A.; AMORIM, R. R. (org.). Os desafios da Geografia Física na fronteira do conhecimento. Campinas: Instituto de Geociências - UNICAMP, 2017.

NASCIMENTO, D. C.; CHACON, S. S. Sustentabilidade na região metropolitana do Cariri - RMC: análise a partir dos objetivos de desenvolvimento do milênio - ODMs. Sociedade e Natureza, v. 28, n. 3, p. 443-456, 2016.

NASCIMENTO, M. A. L. et al. Geodiversidade, geoconservação e geoturismo: trinômio importante para a conservação do patrimônio geológico. Rio de Janeiro: SBGeo, 2008. 
Diagnóstico da relação entre a comunidade e o

Geopark Araripe: geossítios colina do Horto e Pontal da

Santa Cruz, Região Metropolitana do Cariri (RMC),

Ceará

VIANA, M. S. S.; NEUMANN, V. H. L. Membro Crato da Formação Santana, Chapada do Araripe, CE. In: SCHOBBENHAUS, C. et al. Sítios Geológicos e Paleontológicos do Brasil. Brasília: DNPM/CPRM - SIGEP, 2002. 
Diagnóstico da relação entre a comunidade e o

Geopark Araripe: geossítios colina do Horto e Pontal da

Santa Cruz, Região Metropolitana do Cariri (RMC),

ANEXO A - Questionário utilizado na pesquisa de opinião na comunidade do Horto (Juazeiro do Norte, RMC, Ceará)

\section{PESQUISA DE OPINIÃO COM A POPULACÃO DA COLINA DO HORTO - MUNICÍPIO DE JUAZEIRO DO NORTE CEARÁ}

Apresentação: Bom dia meu nome é ___ sou estudante do curso de geografia da Universidade Regional do Cariri e estou fazendo uma pesquisa com os moradores dessa região sobre o seu dia-a-dia. Poderia me ajudar?

\section{Parte 1 - Identificação}

(P1) Nome (p1.1) sexo: F () M () (P.2) Idade

(P.3) Qual sua escolaridade? Analfabeto ( ) fundamental incompleto. ( ) fundamental e médio incompleto ( ) médio completo. ( ) superior incompleto. ( ) superior completo.( ) |Pós -graduado. ( )

(P.4) Qual sua situação econômica? você é trabalhador com vínculo empregatício ( ) trabalhador sem vínculo empregatício ( ) funcionário público procurando emprego ( ) estudante ( ) dona de casa ( ) aposentado ( ) pensionista ( ) outro (P5) Qual a sua religião?

(P.6) Há quanto tempo você mora neste local? Sempre morou ( ) menos de 5 anos ( ) de 5 a 10 anos ( ) mais de 10 anos ( ).

(P.7) Onde você morava anteriormente? Outro bairro( )outro município ( ) outro estado ( ) Qual?

(P.8) Algum membro da sua família que morava aqui foi morar em outro estado? sim ( ) não( ) .

(P8-1) Qual parentesco? filho(a) ( ) irmão(ã) ( ) pai ( ) mãe ( ) tio ( ) tia ( ) primos (a) ( ) outros qual?

(P.9) Você já sentiu vontade de morar em outro lugar? $\operatorname{sim}(\quad)$ não ( ) Por quê

(P.10) Onde você mora, a condição de ocupação é? Próprio seu ou de sua família com escritura( ) Próprio seu ou de sua família sem escritura Alugado ( ) cedido ( ) sitiante ( ) Ocupação ( ) assentamento( ).

(P.11) Quantas pessoas moram na sua casa?

(P.12) Quantas trabalham fora? (P.13) Qual a renda familiar total?

\section{Parte 2-Património Geológico}

(P.14) você sabe o que é um geossítio? (R.U.) sim |não. (P14.1) Acha que ele é importante? sim |não (P14.2) o que ele é?

(P.15) você sabe o motivo que levou essa região a se tornar um geossítio? (R.U.) sim | não. Onde?

(P.16) Você já visitou outros geossítio? (R.U.) sim |não. Quais?

(P.17) você já ouviu falar no Geopark Araripe? (R.U) sim |não

(P17-1) Acha que ele é importante para essa região? ? (R.U) sim |não, Por quê?

(P17-2) Pra você algo mudou desde que ele foi implantado? Sim |não (P17.3) Para melhor? sim | não.

(P.17-4) Existe algo importante nessa região que você gostaria que fosse inserido no roteiro do Geopark Araripe? sim | não

(P17-5) O que falta nesse município para receber visitantes?

(P.18) o que há de mais importante nessa região (juazeiro)?

(P.20) Eu vou ler uma lista de palavras e você vai me dizer, se na sua opinião, ela é ou não patrimônio (R.M.).

( ) Uma casa ( )Um artesanato ( ) O planeta terra () Uma árvore ( ) Uma pedra

( ) Um prédio antigo () Um osso ( ) O homem ( ) Uma rua ( ) Um fóssil

( ) Uma dança ( )O DNA ( )Uma comida ( )Uma novela ( ) Um jacaré

( )Uma lenda/histórica 
Diagnóstico da relação entre a comunidade e o

Geopark Araripe: geossítios colina do Horto e Pontal da

Santa Cruz, Região Metropolitana do Cariri (RMC),

Ceará

ANEXO B - Questionário utilizado na pesquisa de opinião na comunidade do Pontal de Santa Cruz (Santana do Cariri, RMC, Ceará)

\section{PESQUISA DE OPINIÃO COM A POPULACAO DA COMUNIDADE DO PONTAL DE SANTA CRUZ, MUNICIPIO DE SANTANA DO CARIRI, CEARÁ}

Apresentação: bom dia, meu nome é $\quad$ sou estudante e estou fazendo uma pesquisa com os moradores
dessa região sobre o seu dia-a-dia.Poderia me ajudar?

\section{Parte 1 - Identificação}

(P. 1) Nome (p1.1) sexo: F | M (R.U.) (P.2) Idade

(P.3) Qual sua escolaridade? (R.U.) Analfabeto | fundamental incomp. | findamental compl.|médio incompl. | médio compl. |superior incompl. |superior compl. |Pós-graduado.

(P.4) Qual sua situação econômica? você é. (R.U.) trabalhador com vinculo empregatício |trabalhador sem vínculo empregatício |funcionário publico procurando emprego |estudante |dona de casa |aposentado| pensionista| outro

(P.5) Qual a sua religião? você é. (R.U.) católico | Protestante/evangélico/ cristão/crente Espirita kardecista/umbandista/candomble|religioes orientais/judeu/mulçumano não tem religião/nao quis declarar loutro

(P.6) Há quanto tempo você mora neste local? (R.U.) sempre morou |menos de 5 anos de 5 a 10 anos | de 10 anos.

(P.7) Aonde você morava anteriormente? (R.U.) outro bairro/região | outro município |outro estado. Qual?

(P.8) Algum membro da sua família que morava aqui foi morar em outro estado? (R.U.) sim |não. (P8-1) Qual parentesco? filho(a) |irmão(a) |pai/mãe |tio/tia |primos/primas| outro qual?

(P.9) Você já sentiu vontade de morar em outro lugar? (R.U.) sim | não |Por que

(P.10) onde você mora, a condição de ocupação é? (R.U.) Próprio seu ou de sua família com escritura| Próprio seu ou de sua família sem escritura Alugado/sediado/sitiante |Ocupação/assentamento.

(P.11) Quantas pessoas moram na sua casa? (P.12) Quantas trabalham fora? (P.13) Qual a renda familiar total?

\section{Parte 2-Patrimonio Geológico}

(P.14) Você abe o que é um fóssil? (R.U.) sim |não. (P14.1) Acha que ele é importante? sim |não (P14.2) o que ele é?

(P.15) Você já viu ou soube de restos de animais ou plantas nas rochas ou no chão dessa região? (R.U.) sim | não. Onde?

(P.16) Você já visitou um museu? (R.U.) sim |não. Qual?

(P.17) você já ouviu falar no Geopark Araripe? (R.U) sim | não.

(P17-1) Acha que ele é importante para essa região? ? (R.U) sim |não, Por que?

(P17-2) Pra você algo mudou desde que ele foi implantado? Sim |não (P17.3) Para melhor? sim | não

(P.17-4) Existe algo importante nessa região que você gostaria que fosse inserido no roteiro do Geopark Araripe? sim | não

(P17-5) O que falta nesse município para receber visitantes?

(P.18) o que há de mais importante nessa região (Santana)?

(P.19) Você acha que a universidade deveria se aproximar mais dessa região? (R.U.) Sim | não

(P.20) Eu vou ler uma lista de palavras você vai me dizer, se na sua opinião, ela é ou não patrimônio (R.M.).
( ) Uma casa ( )Um artesanato ( ) O planeta terra () Uma árvore ( ) Uma pedra
( ) Um prédio antigo () Um osso ( ) O homem ( ) Uma rua () Um fóssil
( ) Uma dança ( )O DNA ( )Uma comida ( )Uma novela ( ) Um jacaré
( ) Uma lenda/histórica

(P.21) Você já viu alguém vender um fóssil? (R.U.) sim |não (P21.1) Isso é comum? (R.U.) sim | não 


\section{AGRADECIMENTOS}

Agradecemos ao apoio concedido pelo Programa de Bolsas Universitárias da PBU/URCA, junto ao Programa Institucional de Bolsas de Iniciação Científica PIBIC/URCA, na forma das bolsas de Iniciação Científica concedidas à parte das autoras deste artigo, fundamentais para o desenvolvimento do projeto de pesquisa intitulado: "Diagnóstico da relação entre a comunidade e o GeoPark Araripe" (Abr/2016 - Dez/2016).

Os autores agradecem ainda aos demais pesquisadores e membros do NIGEP (grupo de pesquisa vinculado ao Conselho Nacional de Desenvolvimento Científico e Tecnológico - CNPq). Por fim, agradecemos às estudantes do curso de graduação em Geografia da URCA que deram apoio à etapa de campo: Raqueline Landim e Josielly Brasil. 